\title{
The Impact of COVID-19 on European Tourism Industry
}

\section{Haixin $\mathrm{Xu}$}

\author{
Shanghai University, P.R.China \\ Corresponding author.Email:ybxx636@shu.edu.cn
}

\begin{abstract}
This article studies the impact of COVID-19 on the international tourism industry of eight European countries, using the Difference-in-Difference model and data from 2019-2020. It was found that the international tourism of these 8 European countries (4 Northern and 4 Southern European countries) have been negatively affected by COVID-19, both in terms of overall and regional perspectives. Basically, the number of international tourists in European countries has decreased by about $95 \%$, which has caused great trauma to the development of the industry. At the same time, the tourism situation in Northern Europe is worse than that in Southern Europe.
\end{abstract}

Keywords: COVID-19,European countries, International Tourism, Difference-in-difference model.

\section{INTRODUCTION}

As a very important industry in the tertiary industry, the tourism industry itself is vulnerable to external shocks, such as financial crises, earthquakes and other force majeure factors. The development of a country's tourism industry depends on the comprehensive situation at home and abroad. The persistent COVID-19 pandemic has dealt a fatal blow to the global tourism industry in the first half of 2020. COVID-19 broke out in Asia in December 2019 and has spread to Southeast Asia, Europe and other places. Due to the pathological nature of the COVID-19 epidemic, people are highly likely to be infected with the virus under normal contact. Therefore, activities related to crowd gathering behaviour are greatly affected. As a result, the COVID-19 outbreak has caused unprecedented damage to the tourism industry. Almost all tourism industries in the world are subject to certain restrictions, and the inbound and outbound tourism market is in trouble. According to UNTWO (2020), the number of international tourists in the first four months of 2020 has decreased by $44 \%$ compared to 2019 . Therefore, it is very important to systematically study the impact of COVID-19 on the tourism industry.

Although there are many articles about COVID-19, many researchers have not studied the impact of the tourism industry in detail. At the same time, the existing literature does not systematically describe the impact of COVID-19 on the country's international tourism industry. Therefore, this article will analyse the impact of COVID-19 on the tourism industry at the European country level, and briefly propose some suggestions for the development of tourism in the future.

In order to study the impact of COVID-19 on the international tourism industry of European countries, this article will continue to describe the topic in several sections. The next section will provide a literature review of the articles published so far, while the third section will introduce the methodology used in this article. The fourth section will show the empirical results. The fifth section will report conclusions and further suggestions for European tourism.

\section{LITERATURE REVIEW}

At present, there are only a few articles on COVID19 epidemic and tourism. This part will classify the literature or reports into quantitative analysis and qualitative analysis for literature review.

\subsection{The quantitative Analysis}

These articles focus on the COVID-19 epidemic and issues related to tourism demand, tourism behaviour and tourism recovery.

Wang et al. (2020) collect data through questionnaire survey and analysed the relationship between people's perceived travel risk, degree of travel intention and destination from the perspective of music videos to fight against the epidemic [1]. Through this article, we can learn from the side of the COVID-19 epidemic on the 
tourism industry and tourism destinations caused serious impact. For the outbreak of COVID-19 in China, Qiu et al. (2020) conduct a questionnaire survey on the travel needs and social costs of people in severely affected areas based on the special background of COVID-19 [2]. During the virus epidemic, people are willing to actively reduce travel demand to avoid travel risks. From this conclusion, it is obvious that COVID-19 has a great impact on people's original intention to travel.

The outlook for tourism is also facing serious questions, especially cruise industry. The Diamond Princess cruise of Japan in February is also known as the "Horror cruise": of the 728 confirmed cases, 634 are from the cruise ship. At the same time, the cruise industry in the United States, Norway and other countries has been COVID-19 outbreak cluster outbreak. Sharma \& Nicolau (2020) state that these things make the cruise industry in the tourism industry face a huge blow [3]. UNWTO (2020) publishes data show that as of June 2020, the global tourism industry has almost stopped, and the number of international tourists has dropped by $97 \%$ [4]. Travel restrictions are generally imposed on national tourism destinations as a result of the COVID-19 pandemic. In order to change the situation of complete suspension of tourism and uncertain livelihoods of residents, some countries have reopened beach tourism when the growth rate of infection cases has decreased. However, Zielinski \& Botero (2020) find that beach tourism is also at risk of spreading COVID-19 [5].

In order to explore the proportion of people's travel behaviours in the global causes of COVID-19 epidemic, Farzanegan et al. (2021) use the travel data from 2010 to 2019 to speculate the impact of travel behaviours on the epidemic in 2020 . The results show that $1 \%$ of travel accounted for about $1.2 \%$ of COVID-19 deaths. The tourism industry of all countries is looking forward to the turning point of the COVID-19 epidemic and entering the stage of recovery [6]. He \& Peng (2020) study the development of tourism in China under different recovery stages of COVID-19. The longer the recovery period, the more serious the loss of tourism revenue [7]. At the same time, Han et al. (2020) study regional infectious risk prediction of COVID-19 using geographical economy matrix and migration index from China, and finally concluded that the spread of the epidemic is related to the regional economic level [8]. Therefore, when major health emergencies occur, areas with high economic levels should appropriately increase their defensive levels based on their neighbouring geographic relationships to reduce economic losses and the probability of illness.

\subsection{The qualitative analysis}

These articles focus on the impact of COVID-19 on tourism and related organizations or groups.

Sönmez et al. (2020) mainly discuss that in the context of the sluggish tourism industry in the United States, the hotel and other tourism service industries were also severely hit [9]. These scholars also note that this influence has spread to many practitioners. The public health sector at this stage has also received global attention. The IMF (2020) points out that the public health departments of each country should strictly control foreign personnel and strengthen their efforts to cooperate with the public sectors of other countries, so as to minimize the possibility of increasing the number of infected people [10]. Meanwhile, in terms of transportation, Muley et al. (2020) find that transportation restrictions are particularly important for the prevention and control of the epidemic in the early and mid-term [11]. However, some transportation departments have been hit hard during the prevention and control period and have been slow to recover, which requires special attention from the government.

For tourism, the COVID-19 epidemic has hit too hard. Therefore, many scholars are also thinking about how to explore the way of tourism recovery. Sheller (2020) analyses the possibility of rebuilding a more sustainable ecology and economy in Caribbean islands that are highly dependent on tourism [12]. Additionally, Rassy \& Smith (2013) research one of the keys to corresponding major health incidents based on the impact of $\mathrm{H} 1 \mathrm{~N} 1$ on the tourism industry. They suggest that local governments should focus on key points and allocate resources according to the importance of industries in the regional economy [13]. Simultaneously, the direction of tourism medicine began to attract people's attention. Chiodini (2020) states that the government and relevant social institutions begin to pay attention to tourism medicine, and the industry will usher in a new stage of development in the future [14].

For the future of public health and tourism, Durrheim (2020) discusses from a broader perspective that the international health regulations need to be reformed and the moral obligation to respond more quickly and effectively to infectious diseases [15]. Both Zenker \& Kock (2020) and Gretzel et al. (2020) propose that the old paradigm of tourism could be changed and a new tourism path could be opened up with the development of the Internet [16] [17]. The implementation of e-tourism can reduce the impact of external emergencies to a certain extent. 


\subsection{Literature evaluation}

At present, the number of published articles on related topics is not particularly large. Most of them are based on qualitative analysis, and these articles cover many angles. But basically, there are few quantitative analyses involving the impact of major public health events on the tourism industry. In terms of research, many scholars use questionnaires to study the development of tourism under the epidemic or use past data to speculate on the impact of epidemics on tourism. Therefore, future research on covid-19 can be conducted in empirical terms, and can be compared with past major public health events in order to obtain specific experience and applicable recommendations on the development and recovery of the tourism industry.

\section{METHODOLOGY}

Difference-in-difference method is a very important research method for evaluating the effect or impact of unquantifiable events. There are a lot of economics literature based on this method at home and abroad.

\subsection{Parallel trend assumption}

Before officially using the double difference model, we need to establish an assumption. According to the UNWTO (2020), we can find that the trend of monthly international tourist arrivals in Europe is almost the same from 2017 to 2019. More importantly, the specific value increased slightly from 2017 to 2019, but it almost showed a monthly parallel growth.

So, we decide that if the COVID-19 does not break out in 2020, the international tourism arrivals by month will be the same as that in 2019 . The control group in the difference-indifference model in this article uses the monthly data of the number of international tourists from eight countries in 2019. The difference-in-difference model needs to get the "parallel trend assumption" that both the test group and the control group have similar development trends before the outbreak.

\subsection{Difference-in-difference Model}

The specific method for setting up the difference-indifference model in this article is to construct an "epidemic group" that has an outbreak of COVID-19 and a "control group" that has not experienced an epidemic. By controlling other factors, compare the "epidemic group" and "epidemic group" after the outbreak. In order to explore the impact of the epidemic on the international tourism industry of various countries. The variable "epidemic group" is used to reflect whether it is affected by the epidemic (treat). A value of 1 means that the country is a country with a confirmed patient of the
COVID-19 epidemic, and a value of 0 represents the country's 2019 period (that is, no COVID-19). The situation at the time of the epidemic); Use the variable "patient infection diagnosis time (time)" to reflect the time of the country's new coronary pneumonia epidemic. The month with the number of confirmed cases is set to 1 , otherwise it is 0 . In order to study the impact of the epidemic, we set up the interaction term "COVID-19 Infection", which is the intersection of the "epidemic group (treat)" and "diagnosis time (time)". The value of this cross term (time treat) is that when the two variables of treat and time take 1 , this variable takes the value 1 , and the other cases are 0 .

In this form, we divide the sample into 4 groups: the epidemic group before the epidemic (treat $=1$, time $=0$ ), the epidemic group where the epidemic occurred (treat $=1$, time $=1$ ), and the epidemic before the epidemic (corresponding the epidemic group (treat $=0$, time $=0$ ) in the same month of 2019) and the control group (treat $=0$, time $=1$ ) where the epidemic occurred (corresponding to the same month in 2019).

The difference-in-difference model is

$$
\begin{gathered}
\text { lnta }_{i t}=\beta_{0}+\beta_{1} \text { time }_{i t}+\beta_{2} \text { treat }_{\text {it }}+\beta_{3} \text { timetreat }_{\text {it }}+ \\
\beta_{4} \text { lnveer }_{\text {it }}+\beta_{5} \text { lnincome }_{i t}+\varepsilon_{i t}
\end{gathered}
$$

Among them, $i$ represents each country and $t$ represents time. From the Equation (1), the net impact of the COVID-19 epidemic on the international tourism industry of various countries is the coefficient of the cross term timetreat. If the COVID-19 has a positive effect on the international tourism industry, then the coefficient is significantly positive; otherwise, it is negative. After this treatment, other factors that may affect the number of international tourisms, such as climate, will be eliminated.

Among them, $\quad \beta_{2}$ controls the difference between the epidemic group and the control group. $\quad \beta_{1}$ controls time together and bring the impact of the epidemic group in the control group. $\quad \beta_{3}$ is what we really care about, which is a coefficient that can reflect the impact of the epidemic. The specific explanation is as follows: For the control group, that is timetreat $=0$. From Equation (2), the number of international tourists before and after the epidemic is recorded as:

$$
\text { lnta }= \begin{cases}\beta_{0} & \text { when time }=0 \\ \beta_{0}+\beta_{1} & \text { when time }=1\end{cases}
$$

Therefore, before and after the epidemic, the change in the number of international tourists in the control group accounted for $\quad \beta_{2}$. This reflects the influence of other factors in the country on the number of international tourists. For the epidemic group, timetreat=1, and from 
Equation (3), the number of international tourists before and after the epidemic is recorded as:

$$
\text { lnta }= \begin{cases}\beta_{0}+\beta_{2} & \text { when time }=0 \\ \beta_{0}+\beta_{1}+\beta_{2}+\beta_{3} & \text { when time }=1\end{cases}
$$

It can be seen that during the period before and after the epidemic, the changes in the number of international tourists in the epidemic group are $\beta_{1}$ and $\beta_{3}$. Therefore, the "net impact" of the epidemic on the number of international tourists is the coefficient $\beta_{3}$ of the cross term timetreat. If the epidemic has a positive $\beta$ is effect on international tourism, the sign of significantly positive; otherwise, it is negative. After this treatment, the general factors that affect the eight European countries, such as quarters and environment, will be eliminated. Researchers can more accurately estimate the impact of COVID-19 on the number of international tourists in the eight European countries.

\section{EMPIRICAL RESULTS}

\subsection{Data Description}

This article will explore the impacts on the international tourism industry of eight European countries during the outbreak of the COVID-19 epidemic. These eight countries are 4 countries in Southern Europe and 4 countries in Northern Europe which are Greece, Croatia, Italy and Portugal belonging to the southern area and the four Northern European countries Denmark, Iceland, Norway and Finland. This report will use two-year monthly data from 2019 to 2020. The data includes the number of international tourists as the dependent variable, and the real effective exchange rate and the income of each country as the independent variable. In addition, the dividing "time" line of the COVID-19 diagnosis is recognized as the January of 2020, which is based on the WHO. Meanwhile, the data of "treat" of different countries is exposed by WHO. As for other variables, the data on the number of international tourists comes from the United Nations World Tourism Organization, and the real effective exchange rate comes from the International Monetary Fund. The monthly income of each country is calculated through the monthly industrial production index and quarterly GDP which is derived from OECD and Eurostat. This article mainly uses correlation test double difference model to explore the impacts of the COVID19 on the international tourism of eight European countries. The number of international tourists in each country is recorded in lnta (the unit of ta is 10 thousand, which will not be mentioned below). The real effective exchange rate is expressed in lnreer, and the monthly income is lnincome.

Figure 1 and 2 shows that the changes of international tourists (the unit is 10 thousand) between the two year of the former 6 months. It is obvious that the number of tourists in 2020 has shown a sharp decline since February, and reached a tourist trough in April and May compared with those in 2019. Combined with the condition of the outbreak of COVID-19, this article predicts that there is a particularly obvious negative correlation between tourism and the outbreak and spread of COVID-19 in these countries.
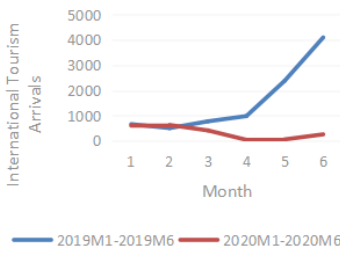

Greece

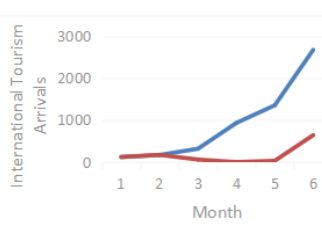

Croatia
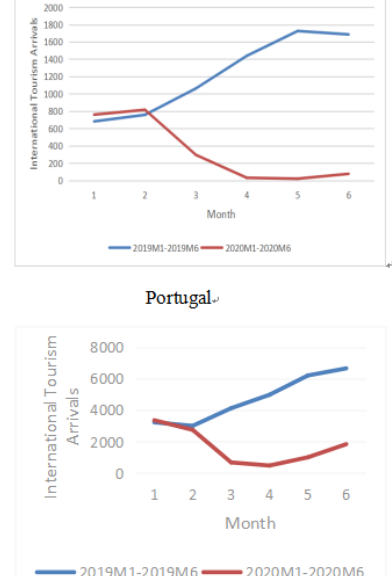

Italy
Figure 1 International tourism arrival changes of 4 Southern countries
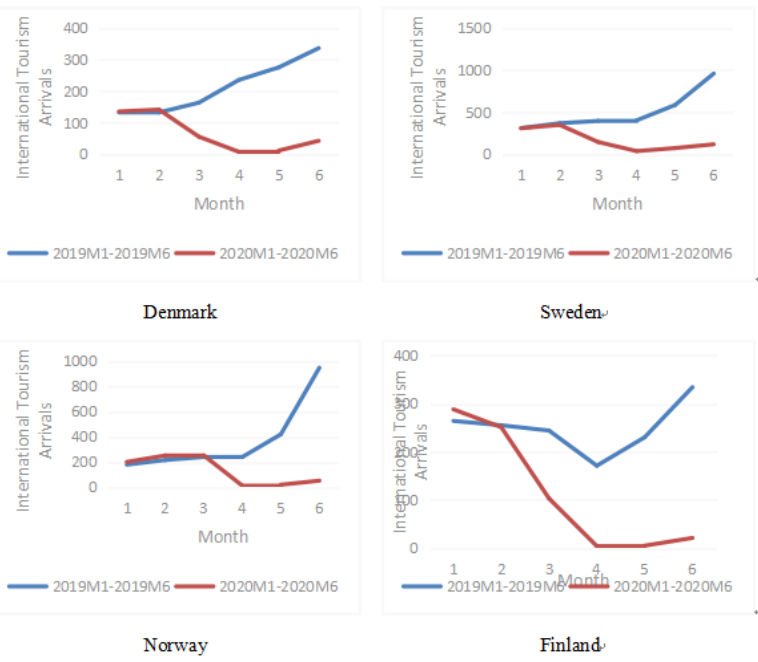

Figure 2 International tourism arrival changes of 4 Northern countries 
Table 1 Descriptive statistics analysis

\begin{tabular}{|c|c|c|c|c|c|c|c|}
\hline Period & Region & Variable & $\begin{array}{l}\text { Numbers of } \\
\text { observations }\end{array}$ & Min & Max & Mean & Std.Dev \\
\hline \multirow{9}{*}{$\begin{array}{c}\text { Before } \\
\text { COVID-19 }\end{array}$} & & lnta & 48 & 4.7875 & 8.3192 & 6.4095 & 1.0472 \\
\hline & $\begin{array}{l}\text { Southern } \\
\text { Europe }\end{array}$ & lnreer & 48 & 4.4886 & 4.6534 & 4.5618 & 0.0557 \\
\hline & & lnincome & 48 & 8.2740 & 9.8056 & 9.3412 & 0.5888 \\
\hline & & lnta & 48 & 4.8828 & 6.8638 & 5.6675 & 0.5172 \\
\hline & $\begin{array}{l}\text { Northern } \\
\text { Europe }\end{array}$ & lnreer & 48 & 4.4365 & 4.5845 & 4.5097 & 0.0629 \\
\hline & & lnincome & 48 & 9.8443 & 10.6150 & 10.2380 & 0.2617 \\
\hline & & lnta & 96 & 4.7875 & 8.3192 & 6.0385 & 0.8989 \\
\hline & All & lnreer & 96 & 4.4365 & 4.6534 & 4.5357 & 0.0644 \\
\hline & & lnincome & 96 & 8.2740 & 10.6150 & 9.7896 & 0.6391 \\
\hline \multirow{9}{*}{$\begin{array}{c}\text { During } \\
\text { COVID-19 }\end{array}$} & & $\operatorname{lnta}$ & 48 & 0.0000 & 6.7032 & 4.2274 & 2.0406 \\
\hline & $\begin{array}{l}\text { Southern } \\
\text { Europe }\end{array}$ & lnreer & 48 & 4.4663 & 4.6829 & 4.5556 & 0.0685 \\
\hline & & lnincome & 48 & 8.1703 & 9.8870 & 9.2623 & 0.6017 \\
\hline & & $\operatorname{lnta}$ & 48 & 1.3863 & 5.8493 & 4.1130 & 1.3998 \\
\hline & $\begin{array}{l}\text { Northern } \\
\text { Eurone }\end{array}$ & lnreer & 48 & 4.2958 & 4.5850 & 4.4805 & 0.0982 \\
\hline & & lnincome & 48 & 9.8522 & 10.5923 & 10.1828 & 0.2548 \\
\hline & & $\operatorname{lnta}$ & 96 & 0.0000 & 6.7032 & 4.2176 & 1.7459 \\
\hline & All & lnreer & 96 & 4.2958 & 4.6829 & 4.5176 & 0.0910 \\
\hline & & lnincome & 96 & 8.1703 & 10.5923 & 9.7190 & 0.6458 \\
\hline
\end{tabular}

Table 1 shows the descriptive statistics analysis of these data. More importantly, these data will be divided into two period (before COVID-19 and During COVID19). Before COVID-19, the maximum of Inta in Southern Europe is about 8.32 which is more than those of Northern countries. The maximum and minimum of lnincome in Southern countries are both larger than those in Northern Europe, while the lnreer in two areas are similar. However, the condition after the outbreak of COVID-19 is different. The first thing should be focused on is the data of lnta. The minimum of this variable in Southern countries decreased to 0 , whereas which of Northern countries stays between 1.39-5.85. Besides, the lnreer and lnincome had a slight reduction approximately. Additionally, there is no significant difference (at $1 \%$ significance) between the Northern and Southern European countries.

\subsection{Data Description}

Through Hausman Test, these sets of data should be used fixed effects. Table 2 is the result of the differencein-difference model obtained by combining all 8 European countries. The coefficient of the timetreat reports that these countries' international tourists number (unit $=1000$ ) was affected by the COVID-19 at about$94.96 \%$, which was significantly negative at the $1 \%$ level. That means approximately $95 \%$ of the previous international tourists whose destination is one of these 8 European countries have not go there in 2020 due to the COVID-19. At the same time, this can also show that the COVID-19 epidemic has hit $95 \%$ of the European tourism industry in these eight countries. 
Table 2 Difference-in-difference model (all countries)

\begin{tabular}{lllll}
\hline \multicolumn{1}{c}{ All countries } & timetreat & Inreer & Inincome & Constant \\
\hline Coefficient & $-0.9496^{* * *}$ & -1.2645 & $5.1186^{* *}$ & $-39.0553^{*}$ \\
Std. Err. & 0.2237 & 3.4836 & 2.0947 & 20.0465 \\
\hline
\end{tabular}

Note: $* * *$ and $* * *$ indicate, significance at, respectively, $10 \%, 5 \%$ and $1 \%$.

Meanwhile, the lnreer and lnincome are negative at about $1.26 \%$ and positive at $5.12 \%$. The real effective exchange rate is inversely proportional to international tourism arrivals---approximately when reer increases by $1 \%$, international tourism arrivals will decrease by $1.26 \%$. Because the increase in the real effective exchange rate will cause the local currency to appreciate, people's purchasing power will decline. And then, the number of inbound tourists will reduce. As for the income, However, every $1 \%$ increase in income of the country will bring about $5.12 \%$ of international tourists.
That could be explained that the local income level affects positively development of the tourism.

Table 3 reveals the influence of COVID-19 to the two different areas, which is divided into Southern Europe and Northern Europe. As can be seen, the timetreat coefficients of Northern Europe and Southern Europe are negative, so the impacts of COVID-19 on the international tourism industry in these two regions is negative. In Southern area, the development of the tourism industry in 2020 has been hampered by approximately $90 \%$. Whereas, in the Northern countries,

Table 3 Difference-in-difference model (Separately)

\begin{tabular}{|c|c|c|c|c|}
\hline & timetreat & Inreer & Inincome & Constant \\
\hline \multicolumn{5}{|c|}{ Southern Europe } \\
\hline Coefficient & $-0.9048 * *$ & 10.1966 & $7.2024^{*}$ & -110.2608 \\
\hline Std. Err. & 0.2755 & 13.9715 & 2.6761 & 72.3598 \\
\hline \multicolumn{5}{|c|}{ Northern Europe } \\
\hline Coefficient & $-1.1269 * * *$ & 3.5361 & -1.6256 & 6.9216 \\
\hline Std. Err. & 0.0834 & 3.9094 & 1.4330 & 18.8210 \\
\hline
\end{tabular}

Note: $* * *$ and $* * *$ indicate, significance at, respectively, $10 \%, 5 \%$ and $1 \%$.

the tourism industry has been hit harder, about $113 \%$ at $1 \%$ significance. Regarding the real effective exchange rate, it has no significant effects on international tourism. However, in terms of income, the international tourism situation of the four Northern countries has been more positively affected, significantly. When income increases by $1 \%$, the number of inbound tourists in Northern Europe will increase by $7.2 \%$, while the coefficient of lnincome in Northern Europe is negative and not significant at $1 \%$. Judging from the results of this article, this shows that the tourist attraction of the Northern Europe is not particularly related to the income of residents. The Northern Europe is in high latitudes, the climate is cold, and the living welfare is ranked high in the world, so tourists who want to travel there basically do not focus on the local economic development. However, there are many countries in Southern Europe, with different geographical locations, and their development status is also inconsistent. Therefore, tourists have included the country's economic development as a basic consideration.

There are three main explanations for the worse performance of the Northern tourism industry in the COVID-19 period. Firstly, the tourism resources of 
Southern Europe have been developed for many years, and the tourism industry in this region is highly organized and comprehensively developed. Bramwell (2003) explains that as early as 2003, the Mediterranean coast of Southern Europe was the main area of world tourism. The tourism industry in Southern Europe is characterized by standardization and scale [18]. Second, the forms of tourism in Southern Europe are more diversified and specialized, especially those related to tourist attractions based on cultural and natural landscapes. Therefore, during the epidemic, southern European countries can relatively adequately make appropriate emergency adjustments to the development of local tourism. Third, the northern countries rely heavily on tourism. Nowak \& Petit (2020) find that throughout Europe, the development of tourism in northern countries is at a relatively disadvantageous position, and other industries will also affect the development of tourism [19]. Therefore, other industries in these countries affected by the epidemic will also indirectly adversely affect the tourism industry. This has also caused a more serious blow to the Northern tourism industry. Therefore, in general, the impact of COVID-19 on the development of the Northern tourism industry is greater.

Analogous to the SARS outbreak of a major global health event in 2003, according to WTTC statistics, the loss of the global tourism industry caused by a major health event of SARS in 2003 was about 30-50 billion US dollars. However, the impact of the 2020 Black Swan event on the global tourism industry far exceeds that of SARS that year. From the empirical results of this article, it can be concluded that due to the impact of COVID-19, the number of international tourists in eight countries in 2020 has dropped by $95 \%$. At the same time, the tourism industry in the Northern region was severely hit. According to the UNWTO (2020), the epidemic has led to a significant reduction in the number of global tourists. In 2020, the global tourism industry will lose 1.3 trillion U.S. dollars in revenue, becoming the "worst year in the history of tourism" [4]. The severe damage caused by COVID-19 to the tourism industry is equivalent to nearly 26-43 times of the 2003 SARS period. This is mainly due to factors such as the strong influence and wide range of the COVID-19 virus. The scope of COVID-19 basically covers the whole world, while SARS mainly operates in Asia and Europe. At the same time, the SARS virus has been eliminated after more than half a year, while the new crown pneumonia virus has continued to this day, and there is a situation that is easy to mutate. In addition, some countries do not pay attention to preventing the COVID-19 virus, artificially promoting the spread of the new crown epidemic. All these make the development of the tourism industry in a disadvantageous position.

\section{CONCLUSIONS AND DISCUSSIONS}

\subsection{Main Conclusions}

This article examines the impact of COVID-19 on the international tourism industry in eight European countries. We divide these places into the Northern Europe and the Southern Europe. In the difference-indifference model, we find that for the entire 8 countries, covid-19 has dealt a 95\% blow to the development of European inbound tourism, which severely hinders the normal development of tourism in this part of the region. At the same time, the empirical results show that the extent to which COVID-19 harms the tourism industry in the Northern countries is stronger than it does to the Southern Europe. In general, it is mainly because the development of tourism in Southern Europe makes it more resistant than the Northern countries. Meanwhile, for countries whose main economic development indicators are the development of tourism, the stable development of tourism is also very important to the country.

\subsection{Implement Further Conclusions}

From the empirical results of this article, it can be concluded that the tourism industry in Northern Europe has suffered more trauma than Southern Europe. At the same time, this article analyzes the reasons why the tourism industry in the Northern region is more fragile. Therefore, this article suggests that the relevant departments of the tourism industry in the Northern region need to pay attention to the systematic development of the tourism industry and learn from the outstanding tourism countries in southern Europe. At the same time, the tourism industry is an environmentally sensitive industry. Any external problems such as major health incidents will lead to the decline of national, regional and even global tourism. Therefore, all countries need to pay attention to major health incidents and take early defenses in order to fundamentally reduce the possibility of severe damage to the tourism industry.

At the same time, this article has some points for improvement. The first point is that there is very little data related to the COVID-19 period. Therefore, the available data period is not very long, and the future can be tracked continuously to obtain more accurate results. The second point is that the tourism industry itself has a certain seasonality, so the harm caused by covid-19 to the tourism industry in different seasons is different. So this point needs further study. The third point is that this article selects four countries in Northern Europe and Southern Europe, which can increase the number of research objects in the future. 


\section{REFERENCES}

[1] Wang, F., Xue, T., Wang, T., \& Wu, B. (2020). The Mechanism of Tourism Risk Perception in Severe Epidemic - The Antecedent Effect of Place Image Depicted in Anti-Epidemic Music Videos and the Moderating Effect of Visiting History. Sustainability (Basel, Switzerland), 12(13), 5454-. https://doi.org/10.3390/su12135454

[2] Qiu, R., Park, J., Li, S., \& Song, H. (2020). Social costs of tourism during the COVID-19 pandemic. Annals of Tourism Research, 84, 102994-102994.

https://doi.org/10.1016/j.annals.2020.102994

[3] Sharma, A., \& Nicolau, J. (2020). An open market valuation of the effects of COVID-19 on the travel and tourism industry. Annals of Tourism Research, 83, 102990-102990. https://doi.org/10.1016/j.annals.2020.102990

[4] World Tourism Organization. (2020). World Tourism Barometer. Madrid.

[5] Zielinski, S., \& Botero, C. (2020). Beach Tourism in Times of COVID-19 Pandemic: Critical Issues, Knowledge Gaps and Research Opportunities. International Journal of Environmental Research and Public Health, 17(19), 1-. https://doi.org/10.3390/ijerph17197288

[6] Farzanegan, M., Gholipour, H., Feizi, M., Nunkoo, R., \& Andargoli, A. (2021). International Tourism and Outbreak of Coronavirus (COVID-19): A Cross-Country Analysis. Journal of Travel Research, 60(3), 687-692. https://doi.org/10.1177/0047287520931593

[7] He, X.R., \& Peng, K.J. (2020). Impact of COVID19 on China's tourism industry: Prediction and Countermeasures. Journal of Sichuan Tourism University, 4, 65-71

[8] Han, Z., Wang, H., Abba, B., \& Cheng, X. (2020). Regional infectious risk prediction of COVID-19 based on geo-spatial data. PeerJ (San Francisco, CA), 8 , e10139-e10139. https://doi.org/10.7717/peerj.10139

[9] Sönmez, S., Apostolopoulos, Y., Lemke, M., \& Hsieh, Y. (2020). Understanding the effects of COVID-19 on the health and safety of immigrant hospitality workers in the United States. Tourism Management Perspectives, 35, 100717-100717. https://doi.org/10.1016/j.tmp.2020.100717

[10] International Monetary Fund. (2020). Special Series on COVID-19 Managing the Impacts of the Coronavirus Guidance on Health Spending Police. Washington.
[11] Muley, D., Shahin, M., Dias, C., \& Abdullah, M. (2020). Role of Transport during Outbreak of Infectious Diseases: Evidence from the Past. Sustainability (Basel, Switzerland), 12(18), 7367-. https://doi.org/10.3390/su12187367

[12] Sheller, M. (2020). Reconstructing tourism in the Caribbean: connecting pandemic recovery, climate resilience and sustainable tourism through mobility justice. Journal of Sustainable Tourism, 1-14. https://doi.org/10.1080/09669582.2020.1791141

[13] Rassy, D., \& Smith, R. (2013). The economic impact of H1N1 on Mexico's tourist and pork sectors. Health $\quad$ Economics, 22(7), 824-834. https://doi.org/10.1002/hec.2862

[14] Chiodini, J. (2020). COVID-19 and the impact on travel health advice. Travel Medicine and Infectious Disease, 36, 101824-101824 https://doi.org/10.1016/j.tmaid.2020.101824

[15] Durrheim, D., \& Baker, M. (2020). COVID-19-a very visible pandemic. The Lancet (British Edition), 396(10248), e17-e17. https://doi.org/10.1016/S0140-6736(20)31675-5

[16] Zenker, S., \& Kock, F. (2020). The coronavirus pandemic - A critical discussion of a tourism research agenda. Tourism Management (1982), 81, 104164-104164. https://doi.org/10.1016/j.tourman.2020.104164

[17] Gretzel, U., Fuchs, M., Baggio, R., Hoepken, W., Law, R., Neidhardt, J., Pesonen, J., Zanker, M., \& Xiang, Z. (2020). e-Tourism beyond COVID-19: a call for transformative research. Information Technology \& Tourism, 22(2), 187-203. https://doi.org/10.1007/s40558-020-00181-3

[18] Bramwell, B. (2003). Coastal mass tourism : diversification and sustainable development in southern Europe . Channel View Publications.

[19] Nowak, J., \& Petit, S. (2020). A reconsideration of tourism specialization in Europe. Tourism Economics: the Business and Finance of Tourism and Recreation, 135481662093750-. https://doi.org/10.1177/1354816620937508 